\title{
Empirical Study on Relationship between Environmental Pollution and Economic Growth of Maldives Using Environmental Kuznets Curve and OLS Method
}

\author{
Amzath Ahmed $^{1}$, Drama BediGuy Herve ${ }^{2} \&$ Laijun Zhao $^{1}$ \\ ${ }^{1}$ School of Management, Shanghai University, No. 99 Shangda Road, Shanghai, China \\ ${ }^{2}$ School of Economics, Shanghai University, No. 99 Shangda Road, Shanghai, China \\ Correspondence: Amzath Ahmed, School of Management, Shanghai University, No. 99 Shangda Road, \\ Shanghai, (20444), China. Tel: 86-135-246-242-30. E-mail: amzath_ahmed@hotmail.com
}

Received: May 6, 2012 Accepted: September 11, 2012 Online Published: October 16, 2012

doi:10.5539/ijbm.v7n21p15 URL: http://dx.doi.org/10.5539/ijbm.v7n21p15

\begin{abstract}
For the past few decades, Maldives government has been showing concern about environmental pollution.Even though Maldives' population is low, factories are less, it still emits huge amounts of carbon every year. Maldives is the first country to announce its decision to make the entire nation a carbon neutral country. The purpose of this study is to test the relationship between environmental pollution and economic growth. This is the first research done using time series data for 34 years from 1975-2008 for Maldives. The famous Environment Kuznets Curve and OSL methods were used to test the hypothesis and relationships. Unit root tests were performed to test the statistical properties of the data used in variables. Results show strong positive relationship between environmental pollution and economic growth. EKC estimation shows Maldives could overcome the rapid rate of environmental pollution by growing its economy at a faster rate. Granger Casualty Test indicates changes in GDP per capita Granger-cause Emission. The result of this study will help the environmental authorities to understand the effects of economic growth on the environmental degradation and manage the environmental problems using macroeconomic methods.
\end{abstract}

Keywords: environment, EKC, GDP, Maldives

\section{Introduction}

Maldives is a small island nation in the Indian Ocean. It has been enjoying average economic growth of around $7.5 \%$ from 1987 to 2006 (PND, 2007). Maldives progresses its economic development jumping from a fisheries based primary economy to tourism based tertiary industry in the early 1970s. Tourism is the largest sector of the Maldives' economy which accounts for one third of its fiscal revenue(Shareef, Hoti, \& Macaleer, 2008). Unlike secondary industry, tourism is less machinery incentive industry,hence some researchers now believe that tourism is pollution free or less pollution industry (Salah \& John, 2005), (Ahmed, 2012).

Maldives with its beautiful environment, clear crystal water and handful of insignificant factories ranked 172 out of 216 countries in the Carbon Emission Rank Report published by the Guardian.co.uk(Simon \& Lisa, 2011).This report shows that Maldives emit 2.3 tons of carbon per person. Therefore,questions discussed in this study are; What is the relationship between environment pollution and economic growth in Maldives?,does Maldives economic growth and carbon emission havea Kuznets relationship andif so when will Maldives economy face the Kuznets turning point, These questions are important to the Maldives' commitment to be the first carbon neutral country in the world by 2020.

\section{Environmental Kuznets Curve}

The Environmental Kuznets Curve(Kuznets, 1955) is named after Russian American economist, Simon Smith Kuznets. He hypothesized environmental degradation and pollution increase in the early stage of economic development and that after reaching a certain level of economic growth environmental degradation will decrease as the economy grows. This implies that high income levels of economic growth lead to improvement in the environment condition. Therefore some economists believe that economic growth is a natural remedy for the environmental pollution and depletion of natural resources (Beckerman, 1992). 
The literature on the EKC is voluminous. The EKC concept became widely discussed starting in the early 1990 s with background study of the World Development Report (Shafil \& Bandyopadhyay, 1992) and study of potential impact of NAFTA (Grossman \& Krueger, 1991). The inverted "U" shaped relationship of the environment degradation and income is supported by enough theoretical evidences. According to EKC concept, Carbon dioxide (CO2) emission (the indicator we used as environmental pollution) is expected to have a positive relationship with the level of economic growth. The existence of $\mathrm{EKC}$ for the global pollutant like $\mathrm{CO}$, results in problems if an international scale has not been agreed upon.

There are different views regarding EKC. The study by(Galeotti, Lanza, \& Pauli, 2006)explained that empirical studies for the EKC hypothesis for $\mathrm{CO} 2$ emission are "at best mixed". The EKC curve for $\mathrm{CO} 2$ emission might not be strong evidence of sustainable development, but we can use international corporations and other ways for sustainable development. Supporting the EKC curve (Munasinghe, 1999)suggest economies can achieve target economic development while maintaining low pollution level.

\section{Model Specifications and Variables}

This paper analyzes the relationship between economic growth and environment pollution in Maldives using time series data. The Hypothesis tested was whether the environmental pollution is positively related to the economic growthor not. In this paper we used linear and non-linear regression models to examine our hypothesis. The Linear Regression Model used is Ordinary Least Square regression model. This model was tested using equation (1) given below:

$$
E=\alpha+\beta_{1} G D P+\beta_{2} P+\varepsilon
$$

Where $\mathrm{E}$ is the Environmental Pollution (in metric tons), GDP is Gross Domestic Product (in million Maldivian Rufiyaaa), P indicates Population (in numbers) and $\varepsilon$ is standard error. In this model we have used the absolute value of the variables. The Population variable is injected as a dummy variable.

The Non-linear regression model used in this study is the EKC model. Most of the EKC model use panel data.In recent years researcheshave been done using time series data. Literature supporting use of time series data for single country in EKC include (Carson, Yongil, \& Donald, 1997), (List \& Gallet, 1999) and (Hannes, 2004). The standard model of EKC using panel data is given in equation (2). The standard EKC model is used to analyze the EKC curve for panel data.

$$
\ln E P_{i t}=\alpha_{i}+\gamma_{t}+\beta_{1} \ln G D P P_{i t}+\beta_{2} \ln G D P P_{i t}{ }^{2}+\varepsilon_{i t}
$$

Where EP refers to environmental degradation per person, GDPP represents the income level per person, and $\varepsilon$ denotes random error and assumed to be independent across the countries. In this model all the variables have been converted in to a natural logarithm. Variables are expressed across a series of countries $(i=1, \ldots \mathrm{N})$ and time periods $(\mathrm{t}=1 \ldots \mathrm{N})$.

If the $\mathrm{EKC}$ hypothesis is met, then equation (2) has a common form, with $\beta_{1}>0$ and $\beta_{2}<0$ for all $\mathrm{i}$, and the income level at the turning point, where environmental quality is not affected by income is given by

$$
\tau=\exp \left[\frac{-\beta_{1}}{2 \beta_{2}}\right]
$$

This study use time series data of single country. The standard EKC equation has been rewritten as given in equation (4), where $t$ represents time periods $(t=1 \ldots N)$.All other variables are the same and represent the same identification. The EKC turning point remains the same and uses the equation given in (4)

$$
\ln E P_{t}=\alpha_{t}+\beta_{1} \ln G D P P_{t}+\beta_{2} \ln G D P P_{t}^{2}+\varepsilon_{t}
$$

\subsection{The Independent Variable}

According to the Maldives Carbon Audit, the major environmental pollution of Maldives is the emission of carbon dioxide (Flora, Khelil, Pichon, \& Tissot, 2010). Maldives use diesel as a main fuel to produce electricity that is required for the nation and diesel fuel is burned in the transport industry as well. We used the data from (CDIAC, 2011) and calculated the emission per person using the population of the respective year. Environmental pollution is used as an independent variable in both testing equations. $\mathrm{CO} 2$ Emission as an environmental deflator is used in studies like (Moomaw \& Unruh, 1997) and (Friedl \& Getzner, 2003). In the 
equation (1) variable $E$ denotes actual value of the carbon emission (metric tons) and variable $E P$ in equation (4) denotes the carbon emission per person (metric tons).

\subsection{The Explanatory Variables}

The main question raised in the study concerns the effect or relationship of economic growth to the environmental degradation. As all the studies regarding this topic, $G D P$ is used as the indicator of economic growth or level of income (Granda, Guillermo, Juan, \& Munoz, 2008). GDP's actual figures (in million) are used to compute the results of equation (1) and GDP per capita obtained by dividing the GDP (in millions) by the population of the respective year used in the model (4). Dummy variable, Population, was added to equation (1) as the majority of the population used diesel to generate economic income and daily livelihood. Variable $P$ used the actual number of population. To satisfy the standard equation of EKC, we have used the $G D P^{2}$ as another variable in equation (2). To reduce the currency fluctuation effect to the $G D P$, we have used the Maldivian Ruifyaa as a value of the $G D P$ throughout the study.

\section{Estimation Method}

Time series properties of the variables were examined before conducting the empirical study. Non-stationary time series data has often been regarded as a problem in empirical analysis. Working with non-stationary variables leads to spurious regression results from which further inference is meaningless when these variables are estimated in their original form. In order to overcome this problem there is a need for testing the stationary of these variables. The unit root tests on all the variables are to determine time series characteristics. Unit root test is important as it shows the number of time the variables have to be differentiated to clear the unit root and make the data stationary. In general variables which are stationary are called I (0) series. Those data which needs to be differenced once in order to obtain stationary are called I (1) series. In testing for stationary, the standard augmented Dickey-Fuller test (Dickey \& Fuller, 1979)and Phillips-Perron (Phillips-Perron, 1988)are performed to test whether or not unit root in the data to establish the properties of individual series. The regression is estimated by equation (5) as follows:

$$
\Delta Y_{t-1}=\alpha+\beta Y_{t-1} \sum_{j=1}^{k} \gamma_{i} \Delta Y_{t-k}+\varepsilon_{t}
$$

Where $\Delta$ is the difference operator, $\mathrm{Y}$ is the series being tested, $\mathrm{K}$ is the number of lagged differences and $\varepsilon$ is the error term. The null hypothesis is that series has a unit root and the alternative hypothesis is that it is stationary. In the case of ADF tests we have considered the usual three cases for the ADF regression: Trend, Trend and Intercept and Non. The number of augmentation terms for the ADF tests were determined by using the Schwarz information criterion (Schwarz, 1978).

After performing the ADF test we performed empirical tests using the equation (1) and equation (4) given above. These two tests were performed to see the relationship between the dependent and independent variables.

Finally we performed the Granger causality test to find out the existence of granger causality among variables in equation (4). The Granger Causality test examines whether the lags of one variable $Y_{l}$ enter into the equation of another variable $Y_{2}$. More precisely, a variable $Y_{1}$ is said to be granger-cause another $Y_{2}$ if the present value of $Y_{2}$ can be predicted with greater accuracy past value of $Y_{l}$ all the information being identical (Thomas, 1997). In the case that $Y_{l}$ Granger-cause $Y_{2}$ but not vice versa, then it can be stated as bi-directional casualty feedback (Brooks, 2002). However it is worth noting that Granger-causality does not mean that movements of one variable physically cause movements of another (Brooks, 2002).

\section{Data Sources}

Maldives started its battle against environmental problems in 1980s. Surprisingly Maldives government failed to maintain environment related data. Specifically no data related to pollution emission was found in any of the statistical data published by the Maldives Government. Environment pollution data used in this study are the data published by the Carbon Dioxide Information Analysis Center (CDIAC, 2011). Carbon emission for Maldives from 1971 till 2008 is available in CDIAC. Gross Domestic Product (GDP) and Population data of Maldives is gathered using different sets of data published by the Maldives Government. Maldives MonitoryAuthority and Ministry of Planning (the name of this ministry has been changed several times) published several key data of the Maldives. The most comprehensive data was the 25 years of data published by (DNP, 2005). From the available data for GDP and Population we decided to use the time series data from 1975 to 2008 . 


\section{Empirical Results and Interpretation}

Before testing the empirical model we analyzed the summary of descriptive statistics of the variables. Absolute data was used to compute the descriptive statistics of the variables. Table $X-1$ shows the sample mean, standard deviation, skewness and Kurtosis, Jacque-Bera statistics and P values for the variables used in OLS Model. According to the data, the results show that the carbon emission of Maldives reached an average of 80 thousand metric tons per year over the past 30 years. The median emission is 50 thousand metric tons. The average emission has increased due to the increase in aviation emission in recent years. Skewness of the variables shows that all the variables, accept population, other two variables are positively skewed, Population is negatively skewed. Kurtosis of Emission and GDP shows leptokurtic distribution and Population shows platykurtic distribution. From the p-Value the null hypothesis that E, GDP and P are normally distributed at $10 \%$ level of significanceand cannot be rejected.

Unit root tests were performed before computing the empirical tests of EKC Model. Our test results of ADF and PP for the time period from 1975 to 2008 are shown in Table X-2. The overall test shows that we fail to reject the stationary null hypothesis base on ADF and PP tests at level except for no trend and no intercept. But all the variables show significant level of accepting null hypothesis at first difference. Thus according to the empirical foundation, we conclude that all variables follow the I(1) process.

Then we performed a correlation test using Ordinary Least Square method for relationship testing model (1) to test the hypothesis. Test results are given in Table X-3. Graph $G-1$, shows the scatter diagram for the variable $E$ and GDP.The graph illustrates positive correlation between 2 variables. The coefficient correlation $R^{2}$ of 0.9855 shows there is very strong correlation between emission and economic growth. F-statistics of 1055.53 and Durbin Watson statistics 1.6807 shows the model is fit to test the hypothesis. This result is in harmony with much of the researches on this topic such as (Egli, 2004). This result interprets that Maldives economy emits around 29000 metric tons of carbon dioxide for every million Rufiyaaa increase in the GDP.

This test result is quite alarming to Maldives who is already facing lots of environmental problems. This result is also not in favor to the Maldives government's declaration of making Maldives as the world first carbon neutral country. This empirical result only shows the relation and direction of the relationship. Hence we performed EKC empirical test to see if Maldives environmental pollution follows the EKCtrend.

We performed EKC empirical test with 34 observations from 1975 to 2008. The result of empirical test is shown in Table X-4. Statistical estimation of the test shows that EKC model is fit to interpret the results. All the coefficients are significant at $1 \%$ level. Representation of the EKC equation for computed data is given below:

$$
\ln E P=-4.4144-3.4165 \ln G D P P-0.6496 \ln G D P P^{2}
$$

Computed results show environmental pollution in Maldives will grow with the growth of GDP per capita till GDP per capita reaches 72100 Rufiyaa. This calculation was processed using equation (3). According to the graph G-1drawn using the results, shows as per capita income increase the emission also increase. At the last year of the collected data, the adjusted emission shows value of 0.75335 per person. The corresponding value of the GDP per capita is 34200 , which is closer to half of the estimated turning income of the EKC. The actual EKC curve for Maldives for the data from 1975-2008 is shown in Graph G-2. Beginning of the curve shows rapid increase in emission as GDP increases. The top of the curve shows the growth of emission has decreased for every increase in GDP. This means that the curve is going to reach its maximum in a near future.

The Granger causality test was performed following the method of (Granger, 1969) and (Sims, 1972). The granger causality test statistics are reported in Table X-5. The statistics reveal changes in GDP per capita Granger cause the carbon emission.

\subsection{Future EKC Curves}

To understand the future EKC curvefor Maldives, we computed the forecast GDP till 2025 using economic growth of $5 \%, 7 \%$ and $9 \%$. The purpose of this estimation is to understand the different EKC turning points at different levels of economic growth. The results of the data used in EKC using equation (4) shows that Maldives will face natural downward slope in emission when the GDP per capita reaches 72100 Rufiyaa. This indicates if Maldives maintainthe same economic growth throughout the years to come, it will reach the turning point in the near future.

Maintaining the same economic growth is very difficult for any country. As Maldives is facing the effect of world economic difficulties, the expected economic growth of Maldives will vary. The average economic 
growth of Maldives is $7 \%$, hence we have used $\pm 2 \%$ from the present economic growth. The summary of the future EKC turning point and expected year for emission per person starts downward slope is shown in Table $X$-6. Graph G-3 to Graph G-5. Computed data shows that at any given growth rate the emission will start declining after reaching the emission per person of 1.08 metric tons.

Our results reveal that the rate of economic growth affects theincome level of the $\mathrm{CO} 2$ turning point. At the rate of 5\% growth emission will start declining when the GDP per capita reach to 71000 Rufiyaa, the year of turning point is estimated to be 2023. On the other hand, emission will reach its peak in 2017 if Maldives economy can maintain an average growth of $9 \%$ per annum with GDP per capita of 74000 Rufiyaa. The forecast results show that if the economy grows at a higher rate the sooner the Maldives economy will encounter EKC turning point. To achieve the national target of carbon neutral economy in 2020, Maldives can use measures to boost its economy and thus reach to EKC turning point sooner than 2020.This study of the relationship between economic growth and environmental pollution gives very important information to Maldives related authorities inmanaging the carbon neutral work.

\subsection{Suggestions to Authorities}

Based on the computed empirical examination and statistical results for the period 1975-2008, we suggest the authorities of the Maldives government:

1) Take measures to reduce its present emission by reducing the consumption of diesel as main source of generating energy needed for its tourism industry and daily livelihood.

2) Adopt strategies to grow economy at a faster rate by using environment friendly methods.

3) Maintain comprehensive environmental data in order to study and understand changes in energy consumption and economic growth in relation to the environmental pollution.

\section{Conclusions}

In this study we have used carbon emission data asthe environmental pollution indicator and GDP as the income indicator. Time series data for 34 years from 1975 to 2008 was used to analyze the relationship between environmental degradation and economic growth. Performed unit root test shows all the variables are stationary at first difference. Ordinary Least Square regression performed using equation (1) shows very high significant relationship between carbon emission and economic growth. This is an expected result as the scatter diagram for the variable shows strong correlation between them.

Testing EKC performed using equation (2) indicates the variables follow significant regression with high regression coefficient. EKC turning point shows that the economy will face the reduction in increase in carbon emission in the near future. Our results are in harmony with the results of other similar studies (Granda, Guillermo, Juan, \& Munoz, 2008), (David \& Carl, 2004).

Our result indicates that Maldives economy can enjoy reduction in the increase in emission if the economy grows at a higher rate. We calculated EKC turning points for economic growth of 5\%, 7\% and 9\% and shows higher rate of economic growth leads to early decline of emission increasing rate. This result will help the environmental authorities to understand the effect of economic growth to the environmental degradation. We assume this study will help the Maldives government to make suitable decisions on achieving carbon neutral country status by 2020 . This study postulates that a country can obtain higher economic growth with better environment by managing the economic indicators. 


\section{References}

Ahmed, N. E. (2012). Tourism is a Pollution free industry: Meira Kumar. Retrieved from http://www.newstrackindia.com/newsdetails/2012/2/1/Tourism-is-a-Pollution-free-industry-Meira-Kumar.h tml

Beckerman, W. (1992). Economic growth and the environment: Whose growth? Whose environment? World Development, 4, 481-496. http://dx.doi.org/10.1016/0305-750X(92)90038-W

Brooks, C. (2002). Introductory Econometrics for Finance. Cambridge University.

Carson, R., Yongil, J., \& Donald, R. (1997). The relationship between air pollution emissions and income: US $\begin{array}{llll}\text { Data. Environment and Development Economics, 2, 43-450. } & \text {. }\end{array}$ http://dx.doi.org/10.1017/S1355770X97000235

CDIAC. (2011). $\mathrm{CO}_{2}$ Emissions from Maldives. Retrieved from http://cdiac.ornl.gov/ftp/trends/emissions/mdv.dat

David, G. E., \& Carl, M. A. (2004). Ruminant Eruction and a Long-Run Environmental Kuznet's Curve for Enteric Methane in New Zealand: Conventional and fuzzy Regression Analysis. Econometrics Working Paper EWP0306: University of Victoria.

Dickey, \& Fuller. (1979). Distribution of the estimators for Autoregressive Time Series with a Unit Root. Journal of the American Statistical Association, 74, 427-431.

DNP. (2005). The 25 Years of Statistics. Retrieved from http://www.planning.gov.mv/publications/25yearsstats/default.htm

Egli, H. (2004). The Environmental Kuznets Curve-Evidence from Time Series Data for Germany. Institute of Economic Research-Economics Working Paper Series.

Flora, B., Khelil, T. B., Pichon, V., \& Tissot, L. (2010). Maldives Carbon Audit. Male: President's office of Rep of Maldives.

Friedl, B., \& Getzner, M. (2003). Determinants of $\mathrm{CO}_{2}$ emissions in a small open economy. Ecological Economics, 45, 133-148.http://dx.doi.org/10.1016/S0921-8009(03)00008-9

Galeotti, M., Lanza, A., \& Pauli, F. (2006). Reassessing the Environmental Kuznets curve for $\mathrm{CO}_{2}$ Emissions: A Robustness Exercise. Ecological Economics, 57, 152-63. http://dx.doi.org/10.1016/j.ecolecon.2005.03.031

Granda, C., Guillermo, L., Juan, P., \& Munoz, C. (2008). The environmental Kuznets Curve for Water Quality: An analysis of its appropriateness using unit root and coinegration tests. Lecturas de economica, pp. 223-244.

Granger, C. (1969). Investigating causal relations by econometric models and corss-spectral methods. Econometrica, 424-438. http://dx.doi.org/10.2307/1912791

Grossman, G., \& Krueger, A. (1991). environmental impacts of a North American Free Trade Agreement. National Bureau of Economic Research Working Paper 3914. Cambridge MA: http://www.nber.org/papers/w3914.pdf

Hannes, E. (2004). The environmental Kuznets Curve-Evidence from Time Series Data for Germany. Zurich: Swiss Federal Institute of Technology.

Kuznets, S. (1955). Economic growth and income inequality. American Economic Review, 49, 1-28.

List, J., \& Gallet, C. (1999). The environmental Kuznets Curve: does one size fit all. Ecological Economics, 31, 409-423. http://dx.doi.org/10.1016/S0921-8009(99)00064-6

Moomaw, W., \& Unruh, G. (1997). Are environmental Kuznets curves misleadingus? The case of CO2 emissions. Environment and Development Economics, 2, 451-463. http://dx.doi.org/10.1017/S1355770X97000247

Munasinghe, M. (1999). Is environmental degradation an inevitable consequence of economic growth: tunneling through the environmental Kuznets curve. Ecological Economics, 29, 89-109. http://dx.doi.org/10.1016/S0921-8009(98)00062-7

Phillips-Perron. (1988). Testing for Unit root in Time Series Regression. Biometrica, 75, 335-346. http://dx.doi.org/10.1093/biomet/75.2.335

PND. (2007). Staff Country Reports. Male: Ministry of Planning and National Development. 
Salah, W., \& John, P. J. (2005). Tourism Development and Growth: The Challange of sustainability. London: Taylor and Francis e-Library.

Schwarz, G. (1978). Estimating Dimensions of a Model. Annals of Statistics, 461-464. http://dx.doi.org/10.1214/aos/1176344136

Shafil, N., \& Bandyopadhyay, S. (1992). Economic Growth and Environmental Quality: The Series and Cross-Country Evidence. Bacground Paper for World Development Report 1992. Washington DC.

Shareef, R., Hoti, S., \& Macaleer, M. (2008). The Economics of Small Island Tourism: International Demand and Country Risk analysis. UK: Edward Elgar Publishing Limited.

Simon, R., \& Lisa, E. (2011, 01). World carbon dioxide emissions data by country: China speeds ahead of the rest. Retrieved from http://www.guardian.co.uk/news/datablog/2011/jan/31/world-carbon-dioxide-emissions-country-data-co 2

Sims, C. (1972). Money Income and Causality. American Economic review, 540-552.

Thomas, R. (1997). Modern Econometrics: an Introduction. Addison-Wesley: Harlow.

\section{Appendix}

Table X-1. Descriptive statistics of variable in model (1)

\begin{tabular}{llll}
\hline Variable/Properties & CO2E (metric tons) & GDP (million Rufiyaaa) & Population \\
\hline Mean & 80558.82 & 4114.676 & 221163.1 \\
Median & 53000 & 3403.7 & 223643.5 \\
Maximum & 251000 & 10594.4 & 309575 \\
Minimum & 2000 & 822.3 & 131786 \\
Std. Dev. & 79138.23 & 2928.514 & 55899.94 \\
Skewness & 0.867153 & 0.681553 & -0.02541 \\
Kurtosis & 2.425519 & 2.295678 & 1.664543 \\
Jarque-Bera & 4.728618 & 3.335011 & 2.530204 \\
Probability & 0.094014 & 0.188717 & 0.28221 \\
Sum & 2739000 & 139899 & 7519544 \\
Sum Sq. Dev. & $2.07 \mathrm{E}+11$ & $2.83 \mathrm{E}+08$ & $1.03 \mathrm{E}+11$ \\
Observations & 34 & 34 & 34 \\
\hline
\end{tabular}

Table X-2.Unit root test

\begin{tabular}{ccccccc}
\hline & \multicolumn{3}{c}{ ADF statistics } & \multicolumn{3}{c}{ Phillips-Perron Statistics } \\
\cline { 2 - 7 } Test Variables & intercept & $\begin{array}{c}\text { Trend and } \\
\text { Intercept }\end{array}$ & None & intercept & $\begin{array}{c}\text { Trend and } \\
\text { intercept }\end{array}$ & None \\
\hline Level & & & & & & \\
$\ln E P$ & $3.4891^{* *}$ & 2.6452 & $8.2951^{*}$ & $4.000^{*}$ & 2.6451 & $7.9473^{*}$ \\
$\ln G D P P$ & 0.0621 & 2.2796 & $8.5335^{*}$ & 0.0599 & 2.7856 & $10.5049^{*}$ \\
$\ln G D P P^{2}$ & 1.0201 & 1.2825 & $9.2274^{*}$ & 1.1767 & 1.2825 & $9.8161^{*}$ \\
\hline First difference & & & & & & \\
$\Delta \operatorname{lnEP}$ & $8.2792^{*}$ & $8.7699^{*}$ & $2.0202^{* *}$ & $7.8890^{*}$ & $8.9242^{*}$ & $4.5185^{*}$ \\
\hline
\end{tabular}




\begin{tabular}{lllllll}
$\triangle \ln G D P P$ & $6.9174^{*}$ & $6.8048^{*}$ & 0.5791 & $7.7178^{*}$ & $7.0339^{*}$ & $2.5287^{* *}$ \\
$\Delta \ln G D P P^{2}$ & $6.1879^{*}$ & $6.2489^{*}$ & 1.2543 & $6.1879^{*}$ & $6.3086^{*}$ & $2.2146^{* *}$ \\
\hline
\end{tabular}

Source: Computation from data used in Regression Analysis

The table Shows unit root tests. The notation $\ln$ EPP and $\ln$ GDPP indicate respectively the Environmental pollution and Gross Domestic Product. The $\Delta$ donates first-difference derivation. The asterisks *, ** and *** denote statistical significance at $1 \%, 5 \%$ and $10 \%$ respectively. Mckinnon (1980) critical values are used for rejection of the Null unit root.

Table X-3. Empirical results of equation (1)

\begin{tabular}{llll}
\hline Variable & Coefficient & t-Statistics & Probability \\
\hline$\alpha$ & 29026.72 & $1.7578^{*}$ & 0.0000 \\
$G D P$ & 34.1202 & $16.0194^{*}$ & 0.0011 \\
$P$ & -0.4017 & $-3.6008^{*}$ & 0.0886 \\
\hline
\end{tabular}

Source: Computation from data used in Regression Analysis

1\% Two-tailed Critical Values: 2.74404, 5\% Two-tailed Critical Values: 2.03951, 10\% Two-tailed Critical Values: 1.6955 . The asterisks $*, * *$ and $* * *$ denote statistical significance at $1 \%, 5 \%$ and $10 \%$ respectively

Table X-4. Empirical results of equation (2)

\begin{tabular}{|c|c|c|c|}
\hline Variable & Coefficient & t-Statistics & Probability \\
\hline$\alpha$ & -4.4144 & $-3.5502 *$ & 0.0000 \\
\hline$L n G D P P$ & -3.4165 & $-5.7719^{*}$ & 0.0000 \\
\hline$L n G D P P^{2}$ & -0.6492 & $-9.3385^{*}$ & 0.0013 \\
\hline
\end{tabular}

Source: Computation from data used in Regression Analysis

1\% Two-tailed Critical Values: 2.74404, 5\% Two-tailed Critical Values: 2.03951, 10\% Two-tailed Critical Values: 1.6955 . The asterisks *, ** and *** denote statistical significance at $1 \%, 5 \%$ and $10 \%$ respectively. $R^{2}=$ 0.9935 , Akaike info crieterion $=-1.7954$, F-Statistics $=2374.53$, Durbin-Watson Statistics $=1.4522$, Probability of $($ F-Statistics $)=0.0000$.

Table X-5. Granger-Causality tests

\begin{tabular}{lcll}
\hline Null Hypothesis & Observations & F-statistics & Probability \\
\hline $\ln G D P P$ does not Granger Cause $\ln E P$ & \multirow{2}{*}{32} & 134.810 & $9 . \mathrm{E}-15$ \\
$\ln E P$ does not Granger Cause $\ln G D P$ & & 1.00763 & 0.3784 \\
$\ln G D P P^{2}$ does not Granger Cause $\ln E P$ & 32 & 324.677 & $1 . \mathrm{E}-19$ \\
$\ln E P$ does not Granger Cause $\ln G D P^{2}$ & & 1.32436 & 0.2827 \\
$\ln G D P P^{2}$ does not Granger Cause $\ln G D P P$ & \multirow{2}{*}{32} & 2.05554 & 0.1476 \\
$\ln G D P P$ does not Granger Cause $\ln G D P P^{2}$ & & 2.41981 & 0.1080 \\
\hline
\end{tabular}

Source: Computation from data used in Regression Analysis

Lags: 2, Sample: 1975-2008 
Table X-6. Estimated turning points at different rate of economic development

\begin{tabular}{llll}
\hline $\begin{array}{c}\text { GDP growth rate } / \\
\text { turning point }\end{array}$ & Year & $\begin{array}{c}\text { Expected GDP/p } \\
\text { (Thousand Ruifyaa) }\end{array}$ & $\begin{array}{c}\text { Expected emission/p } \\
\text { (Metric tons) }\end{array}$ \\
\hline $5 \%$ & 2023 & 71.14 & 1.08 \\
$7 \%$ & 2019 & 72.03 & 1.08 \\
$9 \%$ & 2017 & 74.32 & 1.08 \\
\hline
\end{tabular}

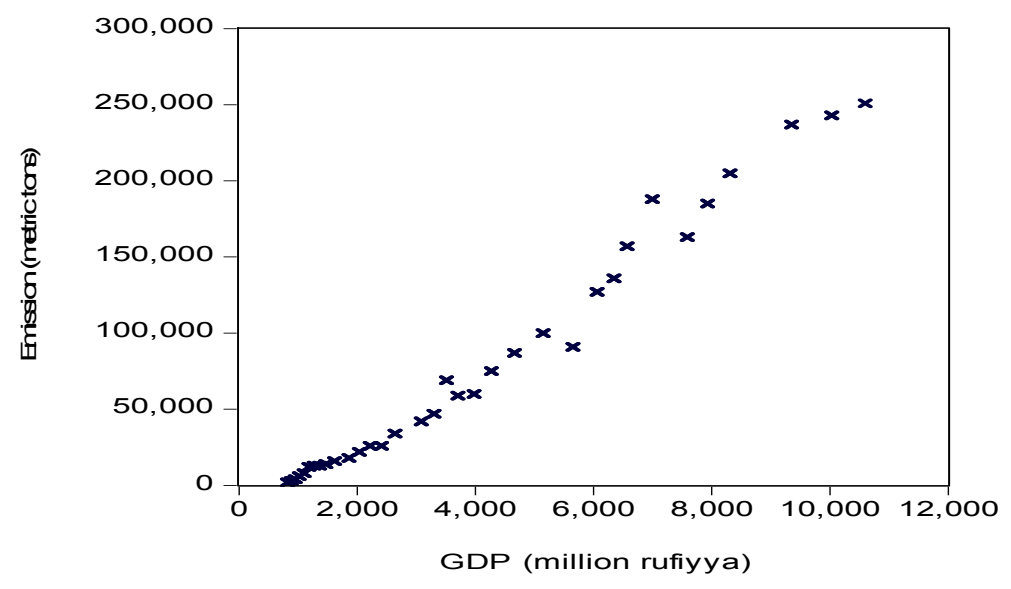

Graph G-1. Scatter diagram of variable E and GDP for equation (1)

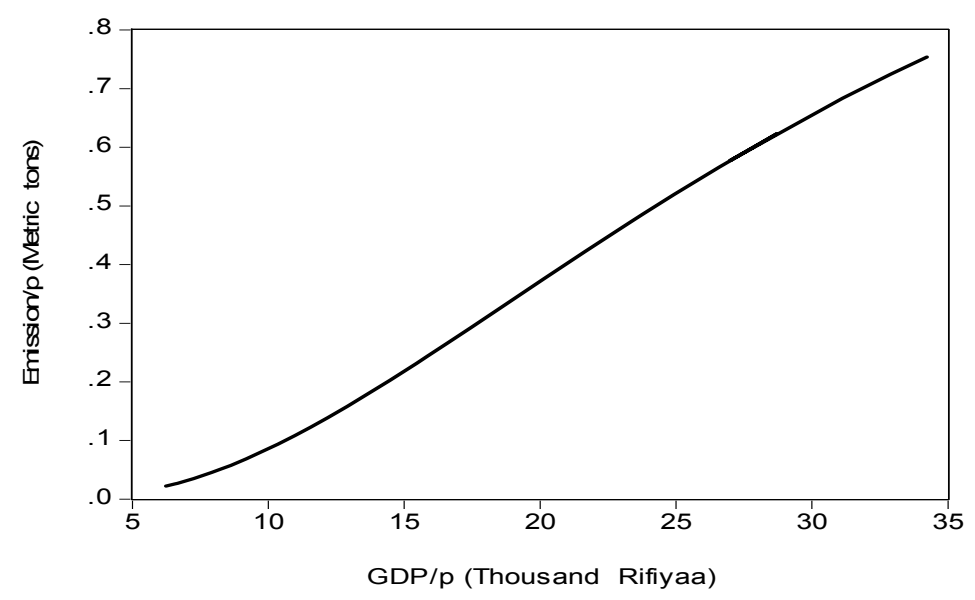

Graph G-2. EKC curve of equation (2) 


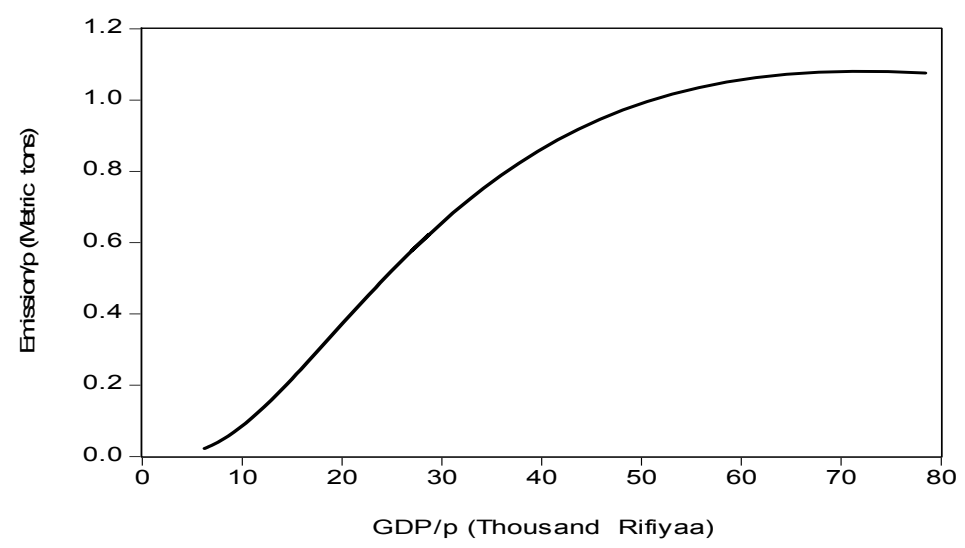

Graph G-3. EKC curve at economic growth of 5\% per year till 2025

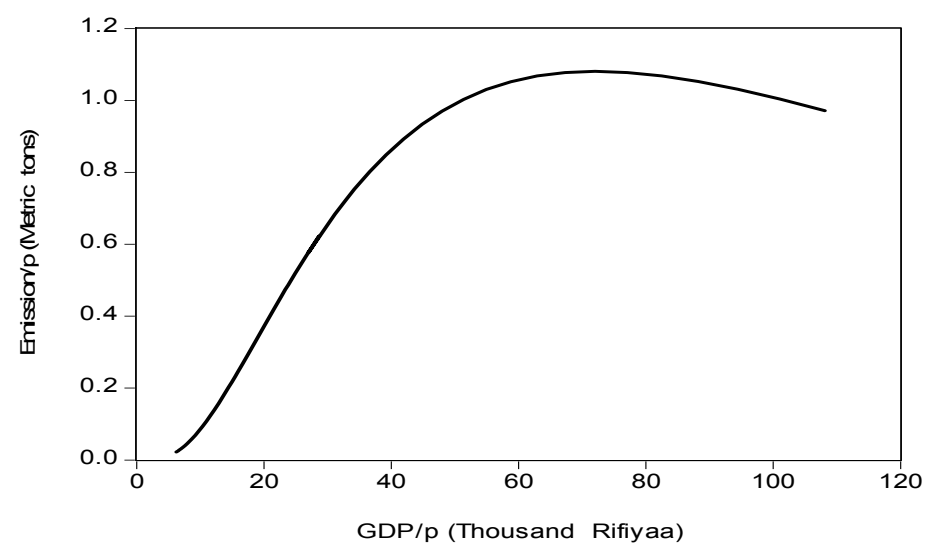

Graph G-4. EKC curve of economic growth at 7\% per year till 2025

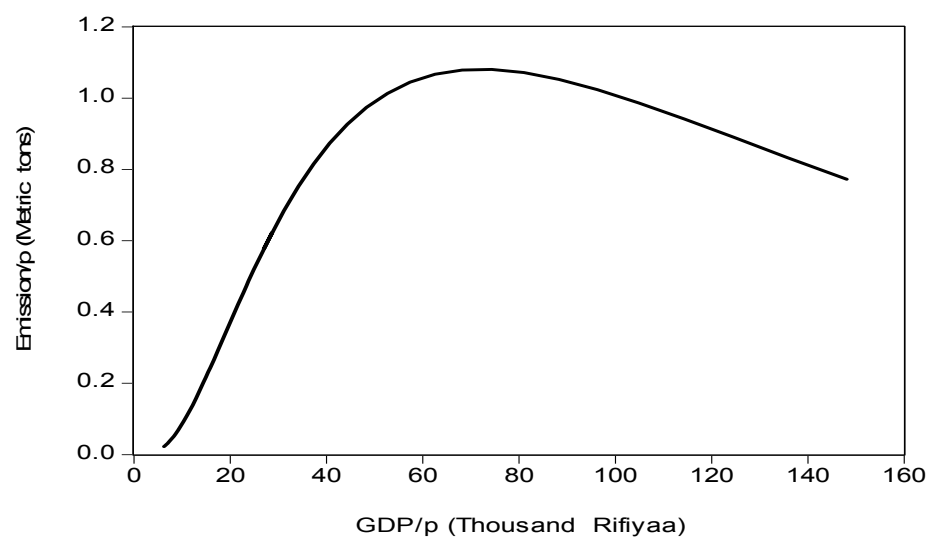

Graph G-5. EKC curve of economic growth at 9\% per year till 2025 